\title{
Bacterial and fungal bloodstream infections in pediatric liver and kidney transplant recipients
}

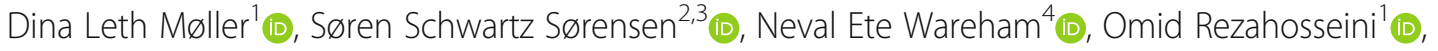 \\ Andreas Dehlbæk Knudsen ${ }^{1,5}$ (D) Jenny Dahl Knudsen ${ }^{6}$ (D) Allan Rasmussen ${ }^{7}$ (i) and Susanne Dam Nielsen ${ }^{1,3^{*}}$ (D)
}

\begin{abstract}
Background: Bacterial and fungal bloodstream infections (BSI) are common after pediatric liver and kidney transplantations and associated with morbidity and mortality. However, knowledge about incidence rates, pathogen composition, and resistance patterns is limited. We aimed to describe the pattern of bacterial and fungal BSI in a cohort of pediatric liver and kidney transplant recipients.

Methods: A prospective study of 85 pediatric liver and kidney transplant recipients transplanted from 2010 to 2017 with a total of 390 person-years of follow-up. Clinical characteristics and BSI were retrieved from national registries assuring nationwide follow-up for at least 1 year. BSI incidence rates and pathogen composition were investigated and stratified by the time post-transplantation and type of transplanted organ.

Results: A total of $29 \mathrm{BSI}$ were observed within the first 5 years post-transplantation with 16 different pathogens. The overall incidence rate of first BSI was 1.91 per 100 recipients per month $(95 \% \mathrm{Cl}, 1.1-3.1)$ in the first year posttransplantation. The most common pathogens were Enterococcus faecium, Candida albicans, Escherichia coli, and Klebsiella pneumoniae. The pathogen composition depended on the transplanted organ with a higher proportion of BSI with Enterobacterales in kidney transplant recipients than in liver transplant recipients (67\% vs. 20\%, $p=0.03$ ), while multiple pathogens were detected in the liver transplant recipients.

Conclusions: BSI were common in pediatric liver and kidney transplant recipients and the pathogen composition differed between liver and kidney transplant recipients. Guidelines for empiric antibiotic therapy should consider the type of transplanted organ as well as the local resistance patterns.
\end{abstract}

Keywords: Liver transplantation, Kidney transplantation, Bacteremia, Fungemia

\section{Introduction}

The outcome of liver and kidney transplantations in children has improved over the last decades with a 5year survival of $85-96 \%$ [1, 2]. However, complications to immunosuppression including severe infections and

\footnotetext{
* Correspondence: sdn@dadlnet.dk

'Viro-immunology Research Unit, Department of Infectious Diseases 8632, Rigshospitalet, University of Copenhagen, Blegdamsvej 9B, DK-2100 Copenhagen $\varnothing$, Denmark

${ }^{3}$ Department of Clinical Medicine, University of Copenhagen, Copenhagen, Denmark Full list of author information is available at the end of the article
}

malignancies still cause substantial morbidity and mortality in these recipients $[1,3,4]$. Infections are associated with allograft dysfunction [1] and are a common cause of death in children after liver and kidney transplantation $[1,4,5]$.

Bacterial and fungal bloodstream infections (BSI) are serious and prevalent infections. Thus, BSI have been reported in up to $25 \%$ of pediatric liver transplant recipients within the first year post-transplantation [6]. Knowledge about the composition of the pathogens that

(c) The Author(s). 2021 Open Access This article is licensed under a Creative Commons Attribution 4.0 International License, which permits use, sharing, adaptation, distribution and reproduction in any medium or format, as long as you give appropriate credit to the original author(s) and the source, provide a link to the Creative Commons licence, and indicate if changes were made. The images or other third party material in this article are included in the article's Creative Commons licence, unless indicated otherwise in a credit line to the material. If material is not included in the article's Creative Commons licence and your intended use is not permitted by statutory regulation or exceeds the permitted use, you will need to obtain permission directly from the copyright holder. To view a copy of this licence, visit http://creativecommons.org/licenses/by/4.0/ The Creative Commons Public Domain Dedication waiver (http://creativecommons.org/publicdomain/zero/1.0/) applies to the data made available in this article, unless otherwise stated in a credit line to the data. 
cause serious infections including BSI is important for the choice of empiric antibiotic therapy and may influence treatment outcome. In adult liver and kidney transplant recipients, the incidence rate (IR) of infections and the pathogen composition (bacteria, fungal, and virus) change during the first year post-transplantation [7]. Little is known about the pattern of infections over time in pediatric liver and kidney transplant recipients. Previous studies on the pathogens causing BSI in pediatric liver and kidney recipients have primarily focused on either the early post-transplantation period $(<6$ months posttransplantation) [8-10] or the late post-transplantation period ( $>6$ months post-transplantation) [11] and studies with a complete follow-up are warranted.

This study was conducted to describe the pattern of bacterial and fungal BSI in pediatric liver and kidney transplant recipients and to provide information for recommendations regarding the use of empiric antibiotic therapy. We prospectively examined all bacterial and fungal BSI in pediatric liver and kidney transplant recipients at a tertiary pediatric transplantation center during the period 2010-2017 to evaluate the BSI incidence rates, BSI pathogen composition, and mortality after BSI during the first year post-transplantation.

\section{Materials and methods}

\section{Study design and participants}

In this prospective study, we included pediatric recipients ( $<18$ years of age) going through the first liver, kidney, or combined liver and kidney transplantation at Rigshospitalet, University Hospital of Copenhagen, Denmark, from January 1st, 2010 to December 31st, 2017. Rigshospitalet is a large tertiary hospital and specialist center of knowledge in transplantation and the only center in Denmark for pediatric liver transplantations. Pediatric liver and kidney transplant recipients were included from the Management of Posttransplant Infections in Collaborating Hospitals (MATCH) cohort [12].

Clinical characteristics including transplantationspecific data and microbiology were retrieved from the Centre of Excellence for Personalized Medicine of Infectious Complications in Immune Deficiency (PERS IMUNE) data repository [13]. Data were generated prospectively as part of the routine care and were merged in the PERSIMUNE data repository. The PERSIMUNE data repository contains data from several national registries and clinical databases including the Danish Microbiology Database $(\mathrm{MiBa})$ that contains data on all microbiological samples from all Departments of Clinical Microbiology in Denmark with samples from both general practice and hospitals with complete coverage since 2010 [14]. From MiBa we received information about all blood cultures, including antibiotic resistance profiles, on all recipients from the day of transplantation to the end of follow-up.

The study was conducted in accordance with the declaration of Helsinki. The retrieval of the data was approved by the National Committee on Health Research Ethics (H-170024315) and the Data Protection Agency (04433, RH-2016-47).

\section{Immunosuppression and antimicrobial prophylaxis}

The standard immunosuppressive regimen after liver and combined liver and kidney transplantation consisted of tacrolimus, mycophenolate mofetil (MMF), and prednisolone (Supplementary material content 1). The standard immunosuppressive regimen in kidney transplantation consisted of induction with basiliximab and tacrolimus, MMF, and prednisolone (Supplementary material content 1). All liver and combined liver and kidney transplant recipients received meropenem $(15 \mathrm{mg} / \mathrm{kg} / 3 x$ day $)$ in the first 5 days post-transplantation. Kidney transplant recipients received a single dose of cefuroxime $(40 \mathrm{mg} / \mathrm{kg})$ preoperatively. High-risk liver and combined liver and kidney $\left(D^{\text {pos }} / R^{\text {pos/- }}\right.$ $\left.{ }^{n e g}\right)$ and all kidney transplant recipients received 3 months of Cytomegalovirus prophylaxis with valganciclovir (dose depending on body surface area and creatinine). Low-risk liver and combined liver and kidney $\left(D^{\text {neg }} / \mathrm{R}^{\text {pos/neg }}\right)$ transplant recipients received 3 months of valaciclovir (dose depending on estimated glomerular filtration rate (eGFR)). Both liver, kidney, and combined liver and kidney transplant recipients received 6 months of trimethoprimsulfamethoxazole $(12.5 / 2.5 \mathrm{mg} / \mathrm{kg} / 2 x$ day 2 days a week) prophylaxis for Pneumocystis jirovecii infection. Neither the liver, kidney, nor combined liver and kidney transplant recipients received further standard prophylactic antifungal treatment. However, further antifungal treatment was used in liver and combined liver and kidney transplantation in certain situations including transplantation due to biliary atresia, acute surgery, and retransplantation among others.

\section{Bloodstream infection}

The blood cultures were drawn on clinical indication. All blood cultures were analyzed using either BACTEC FX $^{\odot}$ (Becton, Dickinson and Company, Franklin Lakes, USA) or BACT/ALERT ${ }^{\odot}$ (Biomérieux, Marcy l'Etoile, France) microbial detection systems. BSI was defined according to the Centers for Disease Control and Prevention (CDC) criteria [15] as an isolation of a bacterial or fungal pathogen from a blood culture that was not attributed to contamination unless the contaminant was isolated on two or more separate occasions within 2 days together with clinical symptoms of infections. Corynebacterium spp. (not Corynebacterium diphtheria), Bacillus spp. (not Bacillus anthracis), Cutibacterium spp., coagulase-negative staphylococci, non-hemolytic streptococci of the viridans group, Aerococcus spp, and 
Micrococcus spp. were regarded as contaminants [15]. Multiple episodes with the same pathogen were considered part of the same infection if they occurred within 14 days after the previous event [16].

Secondary BSI were defined using a modified version of the CDC criteria [16], where BSI were classified as secondary if they occurred within the secondary BSI attribution period ( 3 days before culture to 14 days after) of a culture with the same pathogen from another location than blood (for urine culture: Only cultures with $\geq 10^{5} \mathrm{CFU} / \mathrm{ml}$ ).

The European Committee on Antimicrobial Susceptibility Testing (EUCAST) disk diffusion antimicrobial susceptibility testing method was used to investigate antibiotic resistance [17].

\section{Follow-up}

All recipients were followed from the date of transplantation to the end of follow-up on December 31st 2018, retransplantation, or death, whichever came first. Inclusion stopped on December 31st 2017 to allow for at least 1 year of follow-up for all participants.

Number of BSI, BSI incidence rates, and pathogen composition were reported for the entire follow-up period and divided into four time periods posttransplantation; <1st month, 2nd-6th months, 7th-12th months, and 2nd-5th years post-transplantation. BSI occurring after 5 years of follow-up were not reported.

\section{Statistical analysis}

In all analyses, liver and combined liver-kidney transplant recipients were merged as one group. Proportions were presented as percentages, and continuous data were presented as medians with range. The BSI incidence rates were calculated as the number of first BSI per recipient per person-time at risk in months to account for the different lengths of follow-up in both the liver and kidney transplant recipients and the different time periods post-transplantation. We calculated 95\% confidence intervals $(\mathrm{CI})$ using Byar's approximation to the Poisson distribution. The 5-year cumulative incidence of first BSI for the combined group was calculated using the Aalen-Johansen estimator. Differences in pathogen composition of the BSI stratified by the transplanted organ were calculated using a Fisher's exact test. The probability of survival after a BSI in the first year post-transplantation was calculated using a KaplanMeier estimator. All analyses were conducted in the statistical software R version 3.6.1 [18].

\section{Results}

Characteristics of the pediatric liver and kidney transplant recipients and the blood cultures

We included 85 pediatric liver, kidney, or combined liver and kidney transplant recipients into our cohort
(Table 1) corresponding to all pediatric liver and combined liver and kidney transplantations and 46\% of pediatric kidney transplantations performed in Denmark during the inclusion period. Liver and combined liver and kidney transplantations were more frequent (64\%) than kidney transplantation (36\%). The median age at the time of transplantation was 10.5 years (range 0.6$17.9)$ and there were slightly fewer males (49\%) than females. Eight recipients (9\%) had less than 1 year of follow-up due to early mortality or retransplantation. The median follow-up was 4.6 years (range: 0.01-8.9 years) with a total of 390 person-years of follow-up in the cohort.

A total of 883 blood cultures were drawn on 72 of 85 (85\%) recipients during the first 5 years posttransplantation (Table 2). Of these, 59 blood cultures (7\%) were positive, 805 blood cultures (91\%) were negative, and 19 blood cultures (2\%) were contaminated. The majority of blood cultures were drawn within the first year post-transplantation (64\%).

The 59 positive blood cultures resulted in 29 BSI in 19 (22\%) recipients (Table 2). None of the contaminated blood cultures comply with CDC criteria for BSI. Eleven (13\%) recipients had 1 BSI, 6 (7\%) recipients had 2 BSI, 2 (2\%) recipients had 3 BSI during follow-up. Fifteen out of the 19 recipients with a BSI (79\%), developed their first BSI within the first year post-transplantation. Five out of 29 (17\%) BSI and 20 out of 29 (69\%) BSI were observed in the first month and the first year posttransplantation, respectively.

\section{BSI incidence rate}

The overall incidence rate (IR) of first BSI in the first year post-transplantation in the entire cohort was 1.91 first BSI per 100 recipients per month (95\% CI, 1.1-3.1) corresponding to 22.5 first BSI per 100 recipients per year (95\% CI, 13.2-36.2). The IR of first BSI was highest the first month post-transplantation (6.47 first BSI per 100 recipients per month (95\% CI, 2.5-14.2)) and decreased throughout the year with a lower IR at 2nd-6th month (2.55 first BSI per 100 recipients per month (95\% $\mathrm{CI}, 1.3-4.7))$ and 7th-12th month posttransplantation 0.45 first BSI per 100 recipients per month (95\% CI, 0.1-1.5)).

We observed both fungal (4 out of 20) and bacterial BSI (16 out of 20) in the liver transplant recipients whereas kidney transplant recipients only had bacterial BSI. The IR of first bacterial and first fungal BSI in the liver and combined liver and kidney transplant recipients was 1.67 (95\% CI: 0.8-3.2) and 0.38 (95\% CI: 0.1-1.2) per 100 recipients per month, respectively, in the first year post-transplantation. The IR of first bacterial in the kidney recipients was 1.61 (95\% CI: 0.6-3.5) per 100 recipients per month in the first year post-transplantation. 
Table 1 Patients characteristics

\begin{tabular}{|c|c|c|c|}
\hline & \multirow{2}{*}{$\begin{array}{l}\text { All liver and } \\
\text { kidney } \\
\text { transplant } \\
\text { recipients } \\
n=85\end{array}$} & $\begin{array}{l}\text { Liver and combined liver-kidney transplant } \\
\text { recipients } \\
n=54(64 \%)\end{array}$ & $\begin{array}{l}\text { Kidney transplant recipients } \\
n=31(36 \%)\end{array}$ \\
\hline & & $\begin{array}{l}51(94 \%) \text { deceased-donor liver } \\
\text { transplantations. } \\
3(6 \%) \text { deceased-donor combined liver and } \\
\text { kidney transplantations. } \\
38(75 \%) \text { were split liver transplantations. }\end{array}$ & $\begin{array}{l}18(58 \%) \text { deceased-donor kidney } \\
\text { transplantations. } \\
13(42 \%) \text { living-donor kidney } \\
\text { transplantations. }\end{array}$ \\
\hline Age at transplantation, median (range) & $10.5(0.6-17.9)$ & $10(0.6-17.9)$ & $11.8(1.7-17.9)$ \\
\hline Sex, male (\%) & $42(49 \%)$ & $25(46 \%)$ & $17(55 \%)$ \\
\hline \multirow{7}{*}{$\begin{array}{l}\text { Diseases leading to transplantation, } \\
\text { Numbers of recipients (\% of the recipients in } \\
\text { the transplantation group) }\end{array}$} & & $\begin{array}{l}\text { Cholestatic disease including biliary atresia: } 17 \\
(31 \%)\end{array}$ & Obstructive uropathy: 7 (22\%) \\
\hline & & Metabolic disease: 9 (17\%) & $\begin{array}{l}\text { Hypo/dysplasia of the kidneys: } 4 \\
(13 \%)\end{array}$ \\
\hline & & $\begin{array}{l}\text { Cirrhosis including alfa-1-antitrypsin deficiency } \\
\text { and cystic fibrosis: } 8 \text { (15\%) }\end{array}$ & Congenital nephrosis: 3 (10\%) \\
\hline & & Cancer: 7 (13\%) & $\begin{array}{l}\text { Glomerulonephritis and vasculitis: } 3 \\
(10 \%)\end{array}$ \\
\hline & & Acute liver failure: 5 (9\%) & Other: 5 (16\%) \\
\hline & & Autoimmune hepatitis: 5 (9\%) & Unknown: 9 (29\%) \\
\hline & & Other: 3 (6\%) & \\
\hline
\end{tabular}

Table 2 Blood cultures and bloodstream infections

\begin{tabular}{|c|c|c|c|}
\hline & $\begin{array}{l}\text { All liver and kidney } \\
\text { transplant recipients } \\
N=85\end{array}$ & $\begin{array}{l}\text { Liver and combined liver-kidney } \\
\text { transplant recipients } \\
N=54\end{array}$ & $\begin{array}{l}\text { Kidney transplant } \\
\text { recipients } \\
N=31\end{array}$ \\
\hline $\begin{array}{l}\text { Number of analyzed blood culture } \\
\text { ( } \mathrm{n} \text { of individual recipients (\% of the cohort)) }\end{array}$ & $\begin{array}{l}883 \\
72(85 \%)\end{array}$ & $\begin{array}{l}735 \\
47(87 \%)\end{array}$ & $\begin{array}{l}148 \\
25(81 \%)\end{array}$ \\
\hline \multicolumn{4}{|l|}{ Results of blood cultures } \\
\hline - Positive & $59(7 \%)$ & $48(7 \%)$ & $11(7 \%)$ \\
\hline - Contamination & $19(2 \%)$ & $16(2 \%)$ & $3(2 \%)$ \\
\hline - Negative & 805 (91\%) & $671(91 \%)$ & $134(91 \%)$ \\
\hline $\begin{array}{l}\text { Bloodstream infections }{ }^{\mathrm{b}} \\
\text { ( } \mathrm{n} \text { of individual recipients (\% of the cohort)) }\end{array}$ & $\begin{array}{l}29 \\
19(22 \%)\end{array}$ & $\begin{array}{l}20 \\
12(22 \%)\end{array}$ & $\begin{array}{l}9 \\
7(23 \%)\end{array}$ \\
\hline \multicolumn{4}{|l|}{ Secondary BSI } \\
\hline - Primary (no previous cultivation (\% of all BSI)) & $20(69 \%)$ & $16(80 \%)$ & $4(44 \%)$ \\
\hline - Secondary to cultivation in (\% of all BSI) & $9(31 \%)$ & $4(20 \%)$ & $5(56 \%)$ \\
\hline - Urine & 5 & - & 5 \\
\hline - Drains of the abdomen & 3 & 3 & - \\
\hline - Sputum & 1 & 1 & - \\
\hline $\begin{array}{l}\text { Incidence rate of first BSI per } 100 \text { recipients per month in } \\
\text { the first year post-transplantation }\end{array}$ & 1.91 (95\% Cl: 1.12-3.08) & 2.1 (95\% Cl: 1.08-3.74) & $\begin{array}{l}1.61 \text { (95\% Cl: } 0.61- \\
3.54)\end{array}$ \\
\hline $\begin{array}{l}\text { Incidence rate of first BSI for all liver- and kidney transplant } \\
\text { recipients }\end{array}$ & \multicolumn{3}{|l|}{ Per 100 recipients per month } \\
\hline - 1st month & \multicolumn{3}{|l|}{6.47 (95\% Cl: $2.45-14.17)$} \\
\hline - 2nd-6th month & \multicolumn{3}{|l|}{2.55 (95\% Cl: 1.26-4.66) } \\
\hline - 7th-12th month & \multicolumn{3}{|l|}{0.45 (95\% Cl: 0.09-1.45) } \\
\hline - 1st year & \multicolumn{3}{|l|}{1.91 (95\% Cl: 1.12-3.08) } \\
\hline
\end{tabular}

${ }^{\mathrm{a}}$ One Pediatric blood-culture flask

${ }^{\mathrm{b}}$ After CDC criteria for BSI and 14 days repeat infection timeframe 
The IR of first BSI in the first year post-transplantation (combined bacterial and fungal BSI for the liver transplant recipients and bacterial only BSI for the kidney transplant recipients) is shown in Table 2.

The cumulative incidence of first BSI in the first 5 years post-transplantation for the entire group was 23.06\% (95\% CI: 13.9-32.2) (Fig. 1).

\section{Pathogen composition in the BSI}

In the 29 BSI observed in the first 5 years posttransplantation, 16 different pathogens were isolated (Fig. 2). The most common pathogens were Enterococcus faecium found in 4 out of 29 BSI (14\%), whereas Escherichia coli (E. coli), Klebsiella pneumoniae (K. pneumoniae), and Candida albicans each were found in 3 out of 29 BSI (10\%). Nine BSI (31\%) were classified as secondary BSI (Table 2). In the kidney transplant recipients, all secondary BSI were after a positive urine culture, whereas the liver transplant recipients had secondary BSI after positive cultures in drains of the abdomen (3/ 4) or sputum (1/4). The pathogen composition differed between liver and kidney transplant recipients (Fig. 2). There were significantly more BSI with Enterobacterales in kidney transplant recipients than in liver transplant recipients $(6 / 9(67 \%)$ vs. $4 / 20(20 \%), p=0.03)$. Furthermore, Enterococci spp. and Candida spp. were only observed in liver transplant recipients constituting 6 out of $20(30 \%)$ and 4 out of $20(20 \%)$ of BSI in this group.

\section{Antibiotic resistance profiles}

Antibiotic resistance profiles were available for 27 out of 29 BSI (93\%) (see Tables, Supplementary material content
2 and 3). Extended-spectrum- $\beta$-lactamase producing $E$. coli was observed in one BSI. There were no cultures with either methicillin-resistant Staphylococcus aureus or vancomycin- and/or linezolid resistant enterococci in the cohort. Among all bacterial BSI in the liver transplant recipients, $81 \%$ were susceptible to piperacillin/tazobactam and $81 \%$ to meropenem. Among all bacterial BSI in the kidney transplant recipients, $75 \%$ were susceptible to piperacillin/tazobactam and $88 \%$ to meropenem. All fungal BSI in the cohort were susceptible to fluconazole.

\section{Outcomes after transplantation}

Five out of 54 (9\%) liver transplant recipients and 1 out of 31 (3\%) kidney transplant recipients died during the first year post-transplantation. Three (6\%) liver transplant recipients were retransplanted during the first year post-transplantation. No recipients developed GvHD during the follow-up. One kidney transplant recipient (3\%) was lost to follow-up since the recipient was not a Danish resident. One out of the 15 patients (7\%), who develop a BSI within the first year post-transplantation, died in the first year post-transplantation. The probability of survival after a BSI in the first year posttransplantation was $93 \%$ (95\% CI, 82-100\%) with a median follow-up of 5.0 years.

\section{Discussion}

This study was conducted to provide information about the pattern of BSI in pediatric liver and kidney transplant recipients. BSI were common with an incidence rate of 1.91 first BSI per 100 pediatric liver and kidney transplant recipients per month in the first year post-

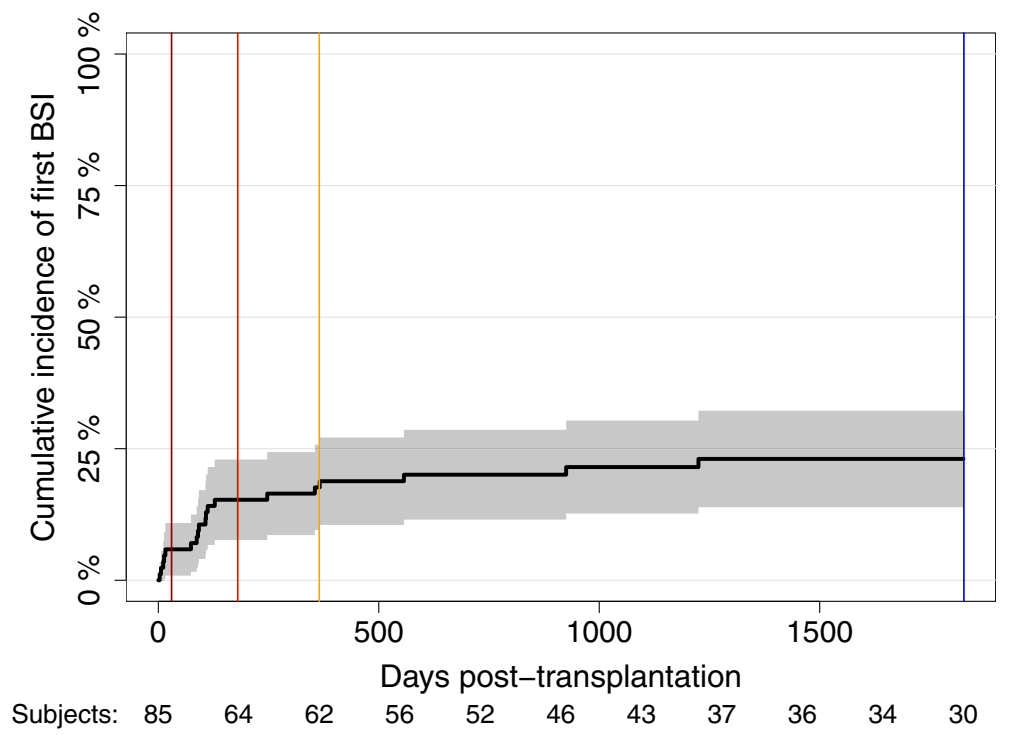

Fig. 1 Cumulative incidence of first bloodstream infections (BSI) in the first 5 years post-transplantation in pediatric liver and kidney transplant recipients. Horizontal lines: Dark red is the first month, red is 6 months, yellow is the first year, and blue is the first 5 years post-transplantation 


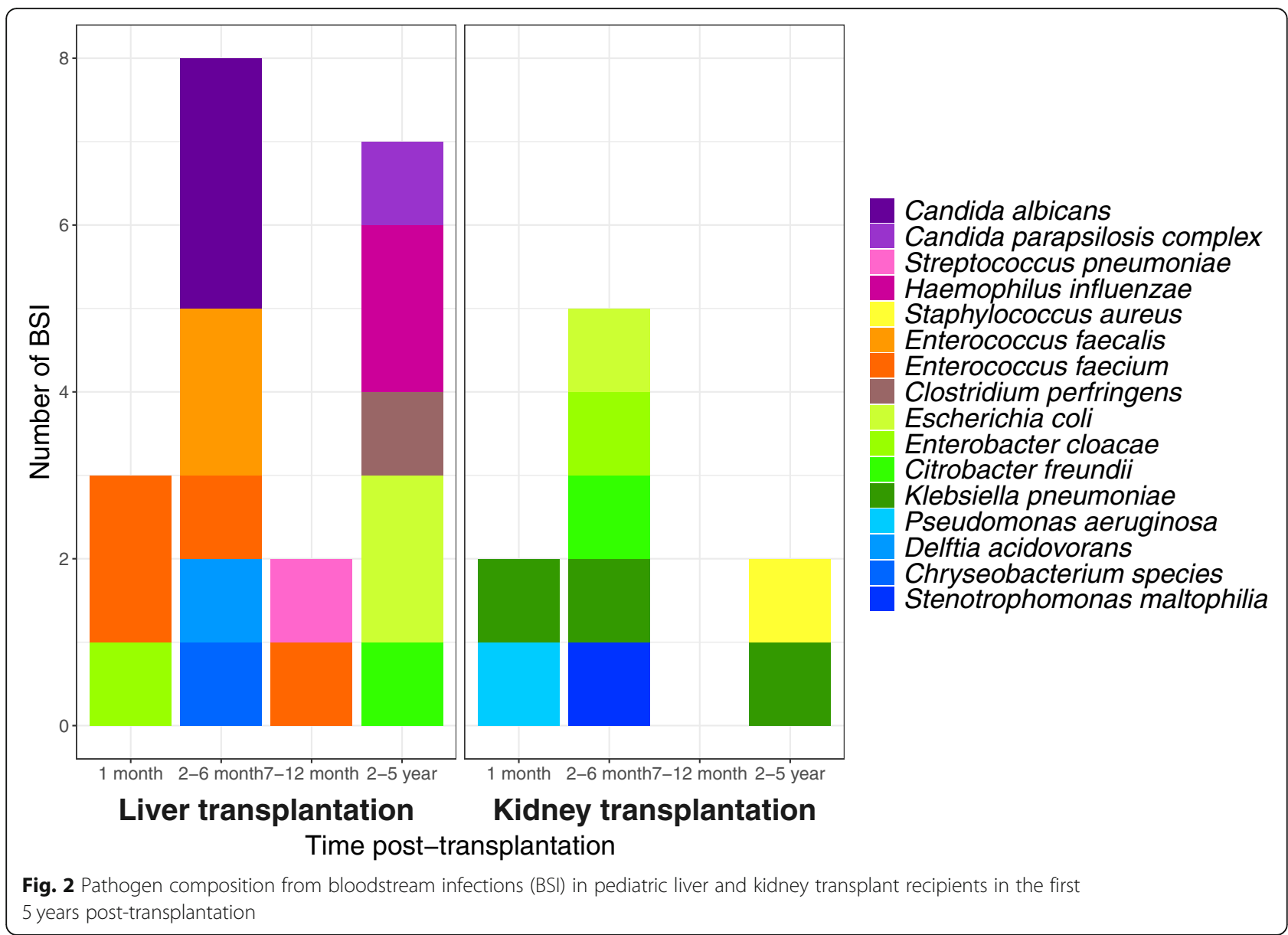

transplantation. The BSI pathogen composition differed between liver and kidney transplant recipients with bacteria from the Enterobacterales group being more common in kidney transplant recipients whereas Candida spp. and Enterococci spp. only were observed in liver transplant recipients.

No previous studies have reported the IR of BSI in pediatric liver and kidney transplant recipients during the entire first year post-transplantation. The overall IR of first BSI in the first year post-transplantation in our study is comparable with data from a nationwide Spanish study of 2935 adult solid organ transplant (SOT) recipients. In this report, the overall IR was 4.8 and 3.0 BSI per 10,000 days post-transplantation in liver and kidney transplant recipients, respectively [19] (corresponding to 1.5-0.9 BSI per 100 recipients per month). Furthermore, a recent study in adult SOT recipients showed that the IR of all infections in liver and kidney transplant recipients was highest during the early post-transplantation period and declined during the first year post-transplantation [7]. We found a similar trend in our cohort with a higher IR in the early post-transplantation period.
With regard to the pathogen composition, we found a higher frequency of BSI with Enterobacterales in kidney transplant recipients than in liver transplant recipients reflecting the high frequency of secondary BSI after urinary tract infection. Similar findings have been reported in adult liver and kidney transplant recipients where Gram-negative bacteria were the major cause of BSI in kidney transplant recipients $[7,19,20]$. The diversity in pathogen composition may also reflect the differences in diseases leading to transplantation in the two groups. We used CDC criteria for BSI which includes bacteria that are normally considered as contaminants including coagulase-negative staphylococci [15]. However, there were no BSI due to coagulase-negative staphylococci or other contaminants in our cohort. In contrast, previous studies that used CDC criteria reported as many as $30 \%$ of BSI being caused by coagulase-negative staphylococci in pediatric liver transplant recipients [6,9]. Furthermore, we found only one case of Staphylococcus aureus which in previous retrospective studies has caused a high proportion of BSI $[6,21]$. However, these studies were conducted in other geographical settings (Japan and the 
USA) where the antibiotic treatment strategies differ from the Danish approach which may, in part, explain the differences. Other explanations may include differences in surgical techniques, the use of intravenous catheters, and immunosuppression regimens between centers.

In our study, candidemia was rare and only found in liver transplant recipients with an IR of 0.38 fungal BSI per 100 recipients per month in the first year posttransplantation. This is in line with a study exclusively investigating invasive fungal disease in 584 pediatric SOT recipients that found no invasive fungal disease in the kidney group, while 27.5 invasive fungal diseases per 100,000 patients days (corresponding to 0.85 events per month per 100 recipients) was found in the liver transplant recipients [22]. However, this study only investigated invasive fungal disease in the first 180 days posttransplantation, and data for the later posttransplantation periods were not available. Since the majority of invasive candida infections have been reported to be from an endogenous source [23], the variation in IR between the liver and kidney transplant recipients may be caused by a higher frequency of candida colonization of the gut compared to the urinary tract.

Only one multidrug-resistant organism, an Extendedspectrum- $\beta$-lactamase (ESBL) producing $E$. coli, was observed in our cohort. This is in contrast to a study investigating severe sepsis in 173 pediatric liver transplant recipients reporting that $47.6 \%$ of the bacterial infections were with multidrug-resistant organisms [24]. However, this study only included a population of highly selected pediatric liver transplant recipients admitted to the pediatric intensive care unit. Furthermore, 24 out of 29 BSI (83\%) were observed after the first month posttransplantation indicating that the majority of the BSI could be community-acquired, thus, lowering the risk of multidrug resistance. The incidence of community-onset ESBL producing $E$. coli and $K$. pneumoniae were found to be between $3-4 \%$ in 2010-2017 in a Danish study [25], supporting our finding of only one ESBL producing E. coli in the six E.coli and K. pneumoniae BSI.

Current reviews of BSI in solid organ transplant recipients including liver and kidney transplantation recommend empiric antibiotic treatment of suspected BSI depending on local epidemiology and previous microbiology data. The antibiotic regimens should cover Gram-negative bacteria and, in the case of intravascular catheters, also Gram-positive bacteria [26, 27]. In our center, the current recommendation for empiric antibiotic treatment of suspected BSI in pediatric liver and kidney transplant recipients is the use of carbapenem. Our findings support the use of empiric carbapenems in pediatric kidney transplant recipients since $88 \%$ of the BSI were susceptible to carbapenem. However, for recently transplanted ( $<12$ months) pediatric liver recipients, additional antibiotic coverage for Enterococcus faecium should be considered such as vancomycin or linezolid depending on local resistance patterns and previous history of vancomycin- and/or linezolid resistant enterococci.

Only one among the 15 recipients with a BSI in the first year post-transplantation died making statistical comparisons in mortality between patients with and without BSI difficult. We found that $8 \%$ of the BSI were due to Streptococcus pneumoniae (S. pneumoniae) and Haemophilus influenzae, which may be prevented by vaccination, highlighting the importance of vaccination prior to transplantation. A recent study of vaccinepreventable infections in 6980 pediatric SOT recipients reported infections with $S$. pneumoniae in $2 \%$ of the recipients and 17 times higher mortality after S. pneumoniae in SOT recipients compared to the general pediatric population [28].

Our study cohort included $68 \%$ of all pediatric liver and kidney transplant recipients transplanted in Denmark during the study period [29]. Nevertheless, groups were small making extrapolation difficult and highlighting the need for cross-national collaborations. Another limitation to the study is the lack of data on use of immunosuppressants and intravenous catheters as well as lack of information on vaccination status. The strengths of our study include the prospective design with long posttransplantation follow-up. The microbiology database $\mathrm{MiBa}$ is nationwide and includes all blood cultures on the recipients sampled in both in- and outpatient facilities as well as in general practice. Furthermore, the Danish Civil Registration System [30] ensures that the vital status is continuously followed for all recipients in the cohort, and we have a near-complete follow-up. Unfortunately, patients migrating and patients from the Faroe Islands and Greenland will be lost to follow-up. However, these patients only represent a small percentage of transplanted children in Denmark. The near-complete follow-up allows us to estimate the IR of BSI in our cohort with a small risk of underestimating the rate.

This study presents incidence rates and pathogen composition for BSI following pediatric liver and kidney transplantation. We found that BSI were common, with an incidence rate of 22.5 first BSI per 100 pediatric liver and kidney transplant recipients in the first year posttransplantation. The BSI pathogen composition differed between liver and kidney transplant recipients, and the empiric antibiotic treatment should depend on the type of transplanted organ and local epidemiology, including pathogen flora and resistance patterns.

\section{Abbreviations}

BSI: Bloodstream infections; CDC: Centers for Disease Control and Prevention; Cl: Confidence intervals; E. coli: Escherichia coli; eGFR: Estimated glomerular 
filtration rate; EUCAST: The European Committee on Antimicrobial Susceptibility Testing; GvHD: Graft-vs-host disease; IR: Incidence rate; $K$. pneumoniae: Klebsiella pneumoniae; MATCH: Management of Posttransplant Infections in Collaborating Hospitals; MMF: Mycophenolate mofetil; MiBa: Danish Microbiology Database; PERSIMUNE: Centre of Excellence for Personalized Medicine of Infectious Complications in Immune Deficiency; SOT: Solid organ transplant; Spp.: Species pluralis; S. pneumoniae: Streptococcus pneumoniae

\section{Supplementary Information}

The online version contains supplementary material available at https://doi. org/10.1186/s12879-021-06224-2.

\section{Additional file 1: Supplementary material content 1.}

Immunosuppressive regimen. Supplementary material content 2.

Antibiotic resistance profiles for bacterial bloodstream infections.

Supplementary material content $\mathbf{3}$. Antibiotic resistance profiles for fungal bloodstream infections

\section{Acknowledgments}

We kindly thank all the liver and kidney transplant recipients and donors and likewise the staff at the transplanting departments, MATCH, and PERSIMUNE for their contribution to this study.

\section{Authors' contributions}

DLM, SSS, NEW, OR, ADK, JDK, AR, and SDN participated in the research design. All authors collected the data. DLM and ADK did statistical analyses. DLM, OR, ADK, SDN participated in writing the manuscript. All authors revised and commented on the manuscript. All authors read and approved the final version of the manuscript.

\section{Funding}

This work was supported by the Novo Nordic Foundation, the Independent Research Fund (FSS), the Danish National Research Foundation (DNRF) grant no. 126, and the Research Foundation of Rigshospitalet. The funding sources were not involved in any part of the study design, data collection, data analysis, and interpretation of the data or the writing of this manuscript.

\section{Availability of data and materials}

The datasets generated and/or analyzed during the current study are not publicly available due to restrictions from the data protection law in Denmark but the data are available to be seen in person at our institution on reasonable request.

\section{Declarations}

\section{Ethics approval and consent to participate}

The study was conducted in accordance with the declaration of Helsinki. The retrieval of the data was approved by the National Committee on Health Research Ethics ( $\mathrm{H}-170024315)$ and the Data Protection Agency $(04433, \mathrm{RH}-$ 2016-47). All relevant approval for this project was obtained from the Danish Health and Medicine Authorities. For this type of study, formal consent is not required according to Danish legislation.

All data was retrieved anonymized from the PERSIMUNE data repository and medical records were not accessed during the study hence no further permissions were needed for the study.

\section{Consent for publication}

Not applicable.

\section{Competing interests}

OR received a grant from The Research Foundation of Rigshospitalet; ADK received a grant from The Danish Heart Foundation and a traveling grant from Gilead not related to this work; NEW received a grant from The Research Foundation of Rigshospitalet; SDN received unrestricted research grants from Novo Nordisk Foundation and Independent Research Fund (FSS) and traveling grants from Gilead and Merck not related to this work; DLM, SSS, JDK, and AR reported no conflict of interest.

\section{Author details}

${ }^{1}$ Viro-immunology Research Unit, Department of Infectious Diseases 8632 , Rigshospitalet, University of Copenhagen, Blegdamsvej 9B, DK-2100 Copenhagen $\varnothing$, Denmark. ${ }^{2}$ Department of Nephrology, Rigshospitalet, University of Copenhagen, Copenhagen, Denmark. ${ }^{3}$ Department of Clinical Medicine, University of Copenhagen, Copenhagen, Denmark. ${ }^{4}$ Centre of Excellence for Health, Immunity, and Infections, Department of Infectious Diseases, Rigshospitalet, University of Copenhagen, Copenhagen, Denmark. ${ }^{5}$ Department of Cardiology, Rigshospitalet, University of Copenhagen, Copenhagen, Denmark. ${ }^{6}$ Department of Clinical Microbiology, Rigshospitalet, University of Copenhagen, Copenhagen, Denmark. ${ }^{7}$ Department of Surgical Gastroenterology and Transplantation, Rigshospitalet, University of Copenhagen, Copenhagen, Denmark.

Received: 26 November 2020 Accepted: 19 May 2021

Published online: 08 June 2021

\section{References}

1. Kim JJ, Marks SD. Long-term outcomes of children after solid organ transplantation. Clinics (Sao Paulo). 2014;69(Suppl 1):28-38. https://doi.org/1 0.6061/clinics/2014(Sup01)06.

2. Jahnukainen $T$, Bjerre A, Larsson M, Tainio J, Thiesson HC, Jalanko H, et al. The second report of the Nordic pediatric renal transplantation registry 1997-2012: more infant recipients and improved graft survivals. Pediatr Transplant. 2016;20(3):364-71. https://doi.org/10.1111/petr.12686.

3. Khan D, Esquivel CO, Makowka L, Madrigal-Torres M, Yunis E, Iwatsukl S, et al. Causes of death after liver transplantation in children treated with cyclosporine and steroids. Clin Transpl. 1989;3:150-5.

4. Foster BJ, Dahhou M, Zhang X, Platt RW, Hanley JA. Change in mortality risk over time in young kidney transplant recipients. Am J Transplant. 2011; 11(11):2432-42. https://doi.org/10.1111/j.1600-6143.2011.03691.x.

5. Shepherd RW, Turmelle Y, Nadler M, Lowell JA, Narkewicz MR, McDiarmid SV, et al. Risk factors for rejection and infection in pediatric liver transplantation. Am J Transplant. 2008;8(2):396-403. https://doi.org/10.1111/ j.1600-6143.2007.02068.x.

6. Shoji K, Funaki T, Kasahara M, Sakamoto S, Fukuda A, Vaida F, et al. Risk factors for bloodstream infection after living-donor liver transplantation in children. Pediatr Infect Dis J. 2015;34(10):1063-8. https://doi.org/10.1097/INF. 0000000000000811.

7. van Delden C, Stampf S, Hirsch HH, Manuel O, Meylan P, Cusini A, et al. Burden and timeline of infectious diseases in the first year after solid organ transplantation in the swiss transplant cohort study. Clin Infect Dis. 2020;71: 159-69.

8. Dohna Schwake C, Guiddir T, Cuzon G, Benissa M-R, Dubois C, Miatello J, et al. Bacterial infections in children after liver transplantation: A singlecenter surveillance study of 345 consecutive transplantations. Transpl Infect Dis. 2019;18:e13208.

9. Rhee KW, Oh SH, Kim KM, Kim DY, Lee YJ, Kim T, et al. Early bloodstream infection after pediatric living donor living transplantation. Transplant Proc. 2012;44(3):794-6. https://doi.org/10.1016/j.transproceed.2012.01.014.

10. Bouchut JC, Stamm D, Boillot O, Lepape A, Floret D. Postoperative infectious complications in paediatric liver transplantation: a study of 48 transplants. Paediatr Anaesth. 2001;11(1):93-8. https://doi.org/10.1046/j.1460-9592.2001. 00574.x.

11. Furuichi M, Fukuda A, Sakamoto S, Kasahara M, Miyairi I. Characteristics and risk factors of late-onset bloodstream infection beyond 6 months after liver transplantation in children. Pediatr Infect Dis J. 2018;37(3):263-8. https://doi. org/10.1097/INF.0000000000001754.

12. Ekenberg C, da Cunha-Bang C, Lodding IP, Sørensen SS, Sengeløv H, Perch $\mathrm{M}$, et al. Evaluation of an electronic, patient-focused management system aimed at preventing cytomegalovirus disease following solid organ transplantation. Transpl Infect Dis. 2020;22(2):e13252. https://doi.org/1 $0.1111 /$ tid. 13252.

13. Centre of Excellence for Personalized Medicine of Infectious Complications in Immune Deficiency (PERSIMUNE). Available from: http://www.persimune. dk/. Cited 2020 Jun 8

14. Voldstedlund M, Haarh M, Mølbak K. The danish microbiology database (MIBA) 2010 to 2013. Eurosurveillance. 2014;19(1):1-7.

15. Horan TC, Andrus M, Dudeck MA. CDC/NHSN surveillance definition of health care-associated infection and criteria for specific types of infections in the acute care setting. Am J Infect Control. 2008;36(5):309-32. https://doi. org/10.1016/j.ajic.2008.03.002. 
16. Centers for Disease Control and Prevention. Identifying Healthcareassociated Infections (HAl) for NHSN Surveillance. 2020. Available from: https://www.cdc.gov/nhsn/PDFs/pscManual/2PSC_IdentifyingHAls_ NHSNcurrent.pdf. Cited 2021 Apr 6

17. Matuschek E, Brown DFJ, Kahlmeter G. Development of the EUCAST disk diffusion antimicrobial susceptibility testing method and its implementation in routine microbiology laboratories. Clin Microbiol Infect Off Publ Eur Soc Clin Microbiol Infect Dis. 2014;20(4):0255-66.

18. R Development Core Team R. R. A Language and Environment for Statistical Computing. Vienna: R Foundation for Statistical Computing; 2011.

19. Moreno A, Cervera C, Gavaldá J, Rovira M, De La Cámara R, Jarque I, et al. Bloodstream infections among transplant recipients: results of a nationwide surveillance in Spain. Am J Transplant. 2007;7(11):2579-86. https://doi.org/1 0.1111/j.1600-6143.2007.01964.x.

20. Silva MJ, Marra AR, Pereira CAP, Medina-Pestana JO, Camargo LFA. Bloodstream infection after kidney transplantation: epidemiology, microbiology, associated risk factors, and outcome. Transplantation. 2010; 90(5):581-7. https://doi.org/10.1097/TP.0b013e3181e8a680.

21. Yin S, Powell EC, Trainor JL. Serious bacterial infections in febrile outpatient pediatric kidney transplant recipients. Pediatr Infect Dis J. 2011;30(2):136-40, https://doi.org/10.1097/INF.0b013e3181f385bf.

22. Saxena S, Gee J, Klieger S, Kajon A, Petersen H, Zaoutis T, et al. Invasive fungal disease in pediatric solid organ transplant recipients. J Pediatric Infect Dis Soc. 2018;7(3):219-25. https://doi.org/10.1093/jpids/pix041.

23. Shoham S, Marr KA. Invasive fungal infections in solid organ transplant recipients. Future Microbiol. 2012;7(5):639-55. https://doi.org/10.2217/ fmb.12.28.

24. Alcamo AM, Alessi $\amalg$, Vehovic SN, Bansal N, Bond GJ, Carcillo JA, et al. Severe Sepsis in pediatric liver transplant patients: the emergence of multidrug-resistant organisms. Pediatr Crit Care Med A J Soc Crit Care Med World Fed Pediatr Intensive Crit Care Soc. 2019;20(7):e326-32.

25. Richelsen R, Smit J, Anru PL, Schønheyder HC, Nielsen H. Incidence of community-onset extended-spectrum $\beta$-lactamase-producing Escherichia coli and Klebsiella pneumoniae infections: an 11-year population-based study in Denmark. Infect Dis (London, England). 2020;52(8):547-56.

26. Guenette A, Husain S. Infectious complications following solid organ transplantation. Crit Care Clin. 2019;35(1):151-68. https://doi.org/10.1016/j. ccc.2018.08.004.

27. Kaviani A, Ince D, Axelrod DA. Management of antimicrobial agents in abdominal organ transplant patients in intensive care unit. Curr Transpl Rep. 2020;7:1-11

28. Feldman AG, Beaty BL, Curtis D, Juarez-Colunga E, Kempe A. Incidence of hospitalization for vaccine-preventable infections in children following solid organ transplant and associated morbidity, mortality, and costs. JAMA Pediatr. 2019;173(3):260-8. https://doi.org/10.1001/jamapediatrics.2018.4954.

29. Scandiatransplant. Available from: http://www.scandiatransplant.org/. Cited 2020 Jun 10

30. Pedersen CB. The Danish civil registration system. Scand J Public Health. 2011;39(7 Suppl):22-5. https://doi.org/10.1177/1403494810387965.

\section{Publisher's Note}

Springer Nature remains neutral with regard to jurisdictional claims in published maps and institutional affiliations.

Ready to submit your research? Choose BMC and benefit from:

- fast, convenient online submission

- thorough peer review by experienced researchers in your field

- rapid publication on acceptance

- support for research data, including large and complex data types

- gold Open Access which fosters wider collaboration and increased citations

- maximum visibility for your research: over $100 \mathrm{M}$ website views per year

At $\mathrm{BMC}$, research is always in progress.

Learn more biomedcentral.com/submissions 